REVIEW

\title{
Management of fluid balance in the very immature neonate
}

\section{N Modi}

Arch Dis Child Fetal Neonatal Ed 2004;89:F108-F111. doi: 10.1136/adc.2001.004275

Preterm birth requires rapid adaptation from a liquid to a gaseous, low humidity environment. There are several ways in which this can be facilitated. The management of sodium and water balance is considered here.

$\mathrm{T}$ he extremely immature infant below 26 weeks gestation is $80-90 \%$ water. $^{1}$ In utero, the baby is immersed in fluid, the lungs are filled with liquid, the skin is porous and lacking a keratin layer; urine output is high, and renal concentrating ability is limited. Preterm birth requires adaptation to an abrupt introduction to a gaseous, low humidity environment. There are many opportunities for the neonatal clinician to help or hinder these processes. This paper will concentrate on the management of sodium and water balance.

\section{WHAT ARE THE DETERMINANTS OF WATER BALANCE?}

Stool water loss is small and usually less than $5 \mathrm{ml} / \mathrm{kg} /$ day in the first days after birth, but losses from the respiratory tract may be high if inspired gases are not adequately humidified. Urine output is variable. The principal determinant of water balance in very immature infants is the extent to which water is lost through the skin. It is also important to recognise the influence of normal physiological adaptations to birth.

\section{TRANSEPIDERMAL WATER LOSS}

Transepidermal water loss (TEWL) reflects both skin immaturity and the large surface area to weight ratio. Recent data suggest that developmentally regulated aquaporin expression in immature skin may also contribute to high TEWL. $^{2}$

The stratum corneum of the skin consists of overlapping, dead, epidermal cells filled with keratin. This layer is the barrier to water loss. Although keratinisation begins at about 18 weeks gestation, the fetal epidermis is still very thin at 26 weeks and the statum corneum barely visible. It is not until 34 weeks gestation that the stratum corneum has become well developed. During the last trimester, the epidermis and stratum corneum thicken, and keratinisation becomes more pronounced. ${ }^{3}$

Skin maturation in preterm infants, unlike the maturation of renal function, is not accelerated by antenatal steroid exposure but is accelerated by birth. ${ }^{34}$ TEWL falls exponentially with increasing postnatal as well as gestational age. ${ }^{5-7}$ In infants born at 24-25 weeks gestation, TEWL is about $60 \mathrm{~g} / \mathrm{m}^{2} / \mathrm{h}$ (about $140 \mathrm{ml} / \mathrm{kg} /$ day in a
$1000 \mathrm{~g}$ baby) at a relative humidity of $50 \%$ in the first two days after birth, decreases significantly by day 3 to around $45 \mathrm{~g} / \mathrm{m}^{2} / \mathrm{h}$ and to $24 \mathrm{~g} / \mathrm{m}^{2} / \mathrm{h}$ by 28 days. $^{8}$ In babies born at lesser degrees of prematurity, by 2-3 weeks of age, skin maturity is similar to that of full term infants. By 32 weeks gestation, TEWL has fallen to the same order of magnitude as full term infants at 6-8 g/m²/h (about $12 \mathrm{ml} / \mathrm{kg} /$ day). ${ }^{3}$

The highest transepidermal losses occur during the first days after birth. ${ }^{8}$ Babies below 28 weeks gestation, nursed naked under radiant warmers, are most vulnerable, and without adequate measures to decrease losses, water lost through the skin may exceed urine volume. Each millilitre of water that evaporates from the skin is accompanied by the loss of 560 calories of heat, and so it is also difficult to keep a baby with a high TEWL warm. Although a radiant warmer can easily provide more heat, this will also increase TEWL. Satisfactory fluid balance and temperature regulation require that the high TEWL of the extremely preterm infant is reduced.

A high ambient humidity reduces TEWL, and this effect is most pronounced in the most immature infants. A decrease in ambient humidity from $60 \%$ to $20 \%$ will increase water lost through the skin by $100 \%$ in infants below 26 weeks gestation. ${ }^{9}$ Takahashi et al ${ }^{10}$ showed that insensible water loss in infants weighing less than $1000 \mathrm{~g}$ is reduced to less than $40 \mathrm{ml} / \mathrm{kg} /$ day if ambient humidity is above $90 \%$. Humidification is easiest in modern, double walled incubators, but this makes access difficult. A high humidity microenvironment above $60 \%$ may be maintained immediately around a baby nursed under a radiant warmer, by using a humidified body hood. "Rain out" may be a problem if the inner surface temperature drops below condensation point. Circumstances in which this typically occurs are when the air temperature but not humidity is reduced in response to a high infant body temperature or when the temperature in the nursery is too low. A randomised controlled trial comparing radiant warmer and incubator care with added humidity in both groups showed better temperature stability in the former group. ${ }^{11}$

At delivery the tiniest of infants benefit from being placed in a plastic bag after drying, while stabilisation procedures are being undertaken. Waterproof coverings in direct contact with the skin should only be used for short periods of time because of the risk of skin maceration. Care should be taken to eliminate draughts, especially if a radiant warmer is used. Radiant heat sources can increase TEWL by a factor of up to $0.5-2$. Phototherapy units are an additional source of 


\section{ANTICIPATE AND PREVENT}

Transepidermal water loss will be high

Glucose requirements will be variable

Parenteral sodium intake is unnecessary until the physiological postnatal

isotonic loss of extracellular fluid is underway

A fluid prescription is a matter of best clinical judgment and is vulnerable to

changing clinical circumstances

The goals of hydration and nutrition are intertwined but distinct
Take active steps to reduce transepidermal losses

Use a volume independent, variable glucose delivery system ${ }^{26}$

Defer maintenance sodium administration until there has been weight loss of the order of $6 \%$ of body weight

Monitor carefully and continuously

Distinguish these goals clearly

\section{DO'S AND DON'TS}

Do not give furosemide routinely with transfusion of packed red cells ${ }^{27}$

Do not use repeated doses of furosemide in the oliguric baby; in the nonoliguric infant doses should be administered at no more than 24 hour intervals

Do not restrict fluid intake routinely whenever signs of a patent ductus arteriosus are present

Do ask yourself if your goal is hydration or nutrition whenever considering a change in fluid intake
Transfusion of packed red cells at $3 \mathrm{ml} / \mathrm{kg} / \mathrm{h}$ does not lead to intravascular volume overload in extremely preterm infants ${ }^{28}$

Furosemide clearance is low and plasma half life exceeds 24 hours in infants $<31$ weeks postconceptional age. ${ }^{29}$ Repeated doses will lead to rapid accumulation and increase the risks of ototoxicity, interstitial nephritis, and ductal patency Restrict only when there is evidence of volume overload; routine fluid restriction will compromise nutrition

If hydration is satisfactory, stepwise increments in fluid intake after birth are unnecessary unless accompanied by a clinically relevant increase in nutrition

\section{MONITORING FLUID BALANCE IN THE IMMEDIATE POSTNATAL PERIOD}

Daily alteration in body weight

Serum sodium

Urine volume
No postnatal weight loss or immediate weight gain is indicative of fluid excess; the usual cause is impaired sodium and/or water excretion

Hyponatraemia suggests water excess; hypernatraemia suggests water deficit $<1 \mathrm{ml} / \mathrm{kg} / \mathrm{h}$ requires investigation; $2-4 \mathrm{ml} / \mathrm{kg} / \mathrm{h}$ suggests normal hydration; $>6-7 \mathrm{ml} / \mathrm{kg} / \mathrm{h}$ suggests impaired concentrating ability or excess fluid administration radiant heat and may increase TEWL by as much as $30 \%$. However, it is unnecessary to increase fluid intake routinely on starting phototherapy if steps have been taken to reduce insensible water loss.

Stripping of the stratum corneum and deeper abrasions of the skin can be avoided by using non-abrasive tape such as micropore and semipermeable membranes beneath neonatal electrodes, urine bags, and transcutaneous oxygen electrodes. ${ }^{9}$ Semipermeable membranes are available in sheet and spray on form (such as Tegaderm and Opsite) and are permeable to gases, including water vapour. Water impermeable barriers, such as soft paraffin, or emollient ointments improve skin condition ${ }^{912}$ and reduce TEWL, but to date have only entered into use to a limited extent. The outcome of current clinical trials evaluating their use is awaited. Hypernatraemic dehydration is the inevitable consequence of a failure to reduce TEWL. Once this has occurred, attempts to correct the problem by increasing the infusion of fixed concentration glucose solution will equally inevitably lead to hyperglycaemia.

\section{POSTNATAL ADAPTATION}

There is an acute contraction of the extracellular compartment in the immediate postnatal period that is delayed in infants with respiratory distress syndrome. ${ }^{13}$ In the era before surfactants were used, this was evidenced clinically by an obvious natriuresis/diuresis that occurred during the time of improvement in respiratory function. ${ }^{13}$ In the healthy newborn infant and in the infant in whom the natural history of classical respiratory distress syndrome has been altered by antenatal steroid treatment and postnatal surfactant, the diuresis occurs more imperceptibly. In both healthy newborns and infants with respiratory distress syndrome, about $10 \%$ of total body water is lost during the first postnatal week,,$^{14}$ and this is marked by postnatal weight loss. The onset of extracellular fluid loss is determined by cardiopulmonary adaptation, principally the fall in pulmonary vascular pressure and not, contrary to popular assumption, to renal maturation. ${ }^{15}$ It is therefore understandable that attempts to improve the course of respiratory distress syndrome with diuretics have not shown benefit. ${ }^{16}$

As extracellular fluid is principally sodium and water, sodium and water balance is negative during this phase of postnatal adaptation. The chief clinical implication of these observations is to delay routine sodium administration until weight loss has been confirmed. Water intake should be tailored to the extent of insensible water loss with an additional renal allowance for urine production limited to $30 \mathrm{ml} / \mathrm{kg}$ /day before the onset of postnatal weight loss, increasing to $60 \mathrm{ml} / \mathrm{kg} /$ day once weight loss is underway. With improvements in antenatal, intrapartum, and immediate neonatal care, the classical course of respiratory distress syndrome with delayed postnatal loss of extracellular fluid and hence the need for extended restriction of intake is becoming much less common.

\section{RENAL WATER HANDLING}

The capacity to concentrate urine develops progressively during postnatal life. In neonates, maximum urine osmolality is about half that of older subjects. This difference is due to shorter loops of Henle, reduced tonicity of the medullary interstitium as urea concentrations are low because of the 
highly anabolic state of the rapidly growing infant, and reduced expression of acquaporin-2. ${ }^{17}$ Higher urine concentrations can, however, be produced under conditions of severe dehydration stress and in response to antenatal glucocorticoid treatment. The clinical situation in which an extremely immature infant becomes dehydrated but continues to pass large volumes of dilute urine is well recognised. Anecdotal experience suggests that this situation may respond to exogenous arginine vasopressin but there has been no formal study reported.

Preterm babies are able to achieve similar minimal urine osmolalities to adults, and diluting ability is unlikely to limit water excretion. The peak urine flow of mature infants given a water load is the same as that of adults when expressed per unit body water. ${ }^{18}$ Coulthard and Hey ${ }^{19}$ showed that healthy preterm babies are able to adjust water excretion when their daily intakes were varied between 95 and $200 \mathrm{ml} / \mathrm{kg}$, sodium intake remaining constant. Extremely immature preterm babies, in whom minimum urine osmolality is of the order of $90 \mathrm{mosm} / \mathrm{kg}$, will be able to achieve a urine flow rate of about $7 \mathrm{ml} / \mathrm{kg} / \mathrm{h}^{19}$

\section{SODIUM REQUIREMENTS}

Renal capacity to both retain and excrete a sodium load is reduced in the very immature baby. Sodium is not lost through the skin because babies born below 36 weeks gestation do not sweat, although this develops within the first two weeks after birth. ${ }^{20}$ Antenatal glucocorticoid treatment accelerates renal tubular maturation. ${ }^{15}$

The preterm infant is most vulnerable to the adverse effects of inappropriate sodium administration in the first few days after delivery. Randomised controlled trials have shown that early sodium administration increases the risks of hypernatraemia, ${ }^{21}$, particularly if TEWL is high and water intake is limited, and increases the risks of respiratory morbidity by impeding the normal, physiological loss of extracellular fluid. ${ }^{22}{ }^{23}$ Subsequently, once nutritional intake is sufficient to support growth, the extremely preterm infant is at risk of chronic sodium depletion. At this stage, an intake of at least $4 \mathrm{mmol} / \mathrm{kg} /$ day is required, or more particularly in the absence of antenatal steroid exposure. ${ }^{24} 25$

\section{"WRITING UP FLUIDS"}

Didactic recommendations for fluid prescriptions are inappropriate, given variations in gestational age, ambient humidity, nursing practices, and clinical condition. Within a neonatal unit, protocols and guidelines ensure internal consistency, but between neonatal units, although the principles that underpin a guideline are shared, final protocols will be determined by local practices. Enteral intake is likely to be small, for at least the first few days after birth, and fluid volumes must be administered parenterally. Firstly, make a judgment of the likely magnitude of insensible water loss, taking into account sources of radiant heat, ambient humidity, and gestational and postnatal age. A rational initial intravenous volume prescription would be the sum of an allowance for urinary water of $30-60 \mathrm{ml} / \mathrm{kg} /$ day plus estimated insensible water loss. ${ }^{20}$ If ambient humidity can be maintained above $70 \%$, this equates to a total infusion volume of about $100 \mathrm{ml} / \mathrm{kg} /$ day for babies of less than $1000 \mathrm{~g}$ birth weight. It is reasonable to start with a $10 \%$ glucose solution, but be prepared to revert to a variable glucose delivery system that allows glucose delivery rate to be altered independently of fluid volume if blood glucose concentrations are unstable. ${ }^{26}$ Once postnatal adaptation is well underway, total infusion volumes should be dictated by nutritional goals and the energy density of the parenteral preparation used.
Enteral feeds are increased incrementally and as tolerated, but there is no evidence that intravenous volumes need similarly to be increased in a stepwise manner.

\section{HAVE WE GOT IT RIGHT?}

Any initial fluid prescription is no more, but also no less, than best clinical judgment. Whether it is a good best estimate will be influenced by clinical circumstances. The adequacy of a fluid prescription should be monitored carefully. Note birth weight, measure serum creatinine, sodium, and potassium, and start measuring urine output immediately after delivery. Although initial serum biochemistry will reflect maternal concentrations, subsequent infant concentrations will need to be assessed against this baseline. Start a parenteral potassium intake at $2 \mathrm{mmol} / \mathrm{kg} /$ day from day 2 and a sodium intake when weight loss of the order of $6 \%$ of birth weight has been achieved. Alter the volume of fluid administered, bearing in mind the requirement for hydration as well as the requirement to fulfil nutritional goals. The former will fall as TEWL decreases with postnatal age; the latter will be determined by the energy density of the parenteral nutrition formulation and the volume and nature of any enteral feed.

Satisfactory management is indicated by initial weight loss followed by weight gain, urine output exceeding $1 \mathrm{ml} / \mathrm{kg} / \mathrm{h}$, and serum electrolyte concentrations within the normal range. Any temptation to alter sodium and potassium intakes in response to minor fluctuations in serum electrolytes should be resisted. Certainly it should not be necessary to "wait for the daily biochemistry" before writing up the day's parenteral nutrition prescription. If unstable biochemistry is expected, parenteral nutrition is probably not indicated.

A reduction in urine output should not be missed. Prerenal failure can lead rapidly to renal failure. Oliguria should be managed by optimising intravascular volume, cardiac output, tissue oxygenation, and peripheral perfusion. Unless you are dealing with acute blood loss, normal saline is the recommended fluid for acute intravascular volume support.

\section{AUDITING PERFORMANCE}

The extent to which TEWL is reduced, hypernatraemic dehydration and hyperglycaemia, hyponatraemia and inappropriate weight gain avoided, and temperature stability maintained may be regarded as indices of the overall quality of nursing and medical care and are suitable measures for longitudinal audit.

\section{REFERENCES}

1 Hartnoll G, Bétrémieux P, Modi N. The body water content of extremely preterm infants at birth. Arch Dis Child Fetal Neonatal Ed 2000;83:F56-9.

2 Ågren J, Zelenin S, Håkansson M, et al. Transepidermal water loss in developing rats: role of aquaporins in the developing skin. Pediatr Res 2003:53:558-65

3 Cartlidge P. The epidermal barrier. Semin Neonatol 2000;5:273-80.

4 Jain A, Rutter N, Cartlidge PH. Influence of antenatal steroids and sex on maturation of the epidermal barrier in the preterm infant. Arch Dis Child Fetal Neonatal Ed 2000;83:F112-16.

5 Hammarlund K, Sedin G. Transepidermal loss in newborn infants III Relation to gestational age. Acta Paediatr Scand 1979;68:795-801.

6 Hammarlund K, Sedin G, Stromberg B. Transepidermal water loss in newborn infants. VII. Relation to postnatal age in very preterm and full term appropriate for gestational age infants. Acta Paediatr Scand 1982;71:369-74.

7 Hammarlund K, Sedin G, Stromberg B. Transepidermal water loss in the newborn. VIII. Relation to gestational age and postnatal age in appropriate and small for gestational age infants. Acta Paediatr Scand 1983;72:721-8

8 Agren J, Sjors G, Sedin G. Transepidermal water loss in infants born at 24 and 25 weeks of gestation. Acta Paediatr 1998;87:1 185-90.

9 Rutter N. Clinical consequences of an immature barrier. Semin Neonatol 2000;5:281-7.

10 Takahashi N, Hoshi J, Nishida H. Water balance, electrolytes and acid base balance in extremely premature infants. Acta Paediatr Jpn 1994;36:250-2.

11 Meyer MP, Payton MJ, Salmon A, et al. A clinical comparison of radiant warmer and incubator care for preterm infants from birth to 1800 grams. Pediatrics $2001 ; 108: 395-401$ 
12 Pabst RC Starr KP, Qaiyumi S, et al. The effect of application of aquaphor on skin condition, fluid requirements and bacterial colonisation in very low birth weight infants. J Perinatol 1999; 19:278-83.

13 Modi N, Hutton JL. 1990 The influence of postnatal respiratory adaptation on sodium handling in preterm neonates. Early Hum Dev 21:11-20.

14 Tang W, Ridout D, Modi N. 1997 Influence of respiratory distress syndrome on body composition after preterm birth. Arch Dis Child Fetal Neonatal Ed 77:F28-31

15 Modi N. Fluid and Electrolyte Balance. In: Rennie J, ed. Roberton's textbook of neonatology. 4th ed. Edinburgh: Churchill Livingston, in press.

16 Brion LP, Soll RF. Diuretics for respiratory distress syndrome in preterm infants. Cochrane Database Syst Rev 2001 ;(2):CD001454.

17 Yasui M, Marples D, Belusa R, et al. Development of urinary concentrating capacity: role of aquaporin-2. Am J Physiol 1996;271:F461-8.

18 McCance RA, Naylor NJB, Widdowson EM. The response of infants to a large dose of water. Arch Dis Child 1954;29:104-9.

19 Coulthard MG, Hey EN. Effect of varying water intake on renal function in healthy preterm babies. Arch Dis Child 1985;60:614-20.

20 Harpin VA, Rutter N. Sweating in preterm babies. J Pediatr 1982;100:614-19.
21 Shaffer SG, Meade VM. Sodium balance and extracellular volume regulation in very low birth weight infants. J Pediatr 1989;1 15:285-90.

22 Hartnoll G, Bétrémieux P, Modi N. Randomised controlled trial of postnatal sodium supplementation on body composition in 25-30 week gestation infants. Arch Dis Child Fetal Neonatal Ed 2000;82:F24-8.

23 Costarino AT, Gruskay JA, Corcoran L, et al. Sodium restriction versus daily maintenance replacement in very low birth weight premature neonates: a randomised, blind therapeutic trial. J Pediatr 1992;120:99-106.

24 Modi N. Hyponatraemia in the newborn. Arch Dis Child Fetal Neonatal Ed 1998;78:F81-4.

25 Haycock GB. The influence of sodium on growth in infancy. Pediatr Nephrol 1993;7:871-5.

26 Al-Rubeyi B, Murray N, Modi N. A variable dextrose delivery system for use in neonatal intensive care. Arch Dis Child Fetal Neonatal Ed 1994:70:F79.

27 Betremieux P, Hartnoll G, Modi N. Should frusemide be prescribed after packed red cell transfusion in the newborn? Eur J Pediatr 1997;156:88-9.

28 Rascher W, Lingens N, Bald M, et al. Atrial natriuretic peptide and blood volume during red cell transfusion in preterm infants. Arch Dis Child 1991 66:395-7.

29 Mirochnick MH, Miceli JJ, Kramer PA, et al. Furosemide pharmacokinetics in very low birth weight infants. J Pediatr 1988;112:653-7.

\section{CORRECTION}

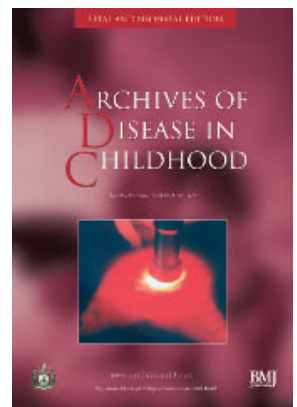

We failed to credit Dr M Masand, who kindly provided the cover image entitled "Cold light examination for diagnosis of pneumo-thorax in newborns - a vanishing skill" (pictured here) for the January 2003 issue of $A D C$ Fetal and Neonatal Edition (Arch Dis Child Fetal Neonatal Ed 2003; 89(1)). We would like to 